MEMÓRIA

\title{
FNDCT, 40 Anos
}

Waldimir Pirró e Longo

Núcleo de Estudos Estratégicos da UFF

Maria Sylvia Derenusson

Financiadora de Estudos e Projetos - FINEP

A história dos 40 anos do Fundo Nacional do Desenvolvimento Científico e Tecnológico-FNDCT (1969-2009) pode ser relatada paralelamente à evolução do sistema que foi estruturado, após a Segunda Grande Guerra, para o desenvolvimento da ciência e da tecnologia no Brasil.

A observação da evolução dos sistemas nacionais de ciência e tecnologia de diferentes países em desenvolvimento permite, didaticamente, dividi-la em quatro estágios ao longo do tempo (Paulinyi, 1986).

O primeiro estágio é caracterizado pela não existência de políticas e estratégias governamentais em C\&T, ocorrendo o que se poderia chamar de uma nucleação aleatória de competências. Os órgãos de pesquisa e de serviços técnicos e científicos são criados pelo governo sem uma visão sistêmica, mas para atender peculiaridades nacionais e emergências conjunturais, principalmente em saúde, agricultura, saneamento e defesa. Poucos pesquisadores são formados e, quando no exterior, geralmente por iniciativa própria.

No segundo, atendendo a uma disposição política governamental, passa a ocorrer uma nucleação programada, quando deliberadamente são criados um a um os componentes necessários à formação de um sistema de C\&T. A estratégia utilizada nesse estágio é simplesmente povoar o sistema mediante a formação de recursos humanos altamente qualificados, implantação da infraestrutura física (estatal e privada), 
criação de instituições de fomento e de fundos públicos para financiar pesquisas, organização dos pesquisadores em associações científicas, criação de revistas, realização de congressos etc. Em outras palavras, os quatro setores (governo, educação, empresas e comunidade científica) são providos de órgãos e de meios de atuação.

No terceiro estágio, ocorre o crescimento e interação mútua dos componentes do sistema que já está delineado e funciona ainda meio desarticulado. Porém, aos poucos, as políticas vão sendo adequadas e aperfeiçoadas. Os integrantes do sistema são fortalecidos, completados e expandidos. Os incentivos creditícios, fiscais, não fiscais e de mercado são criados.

Nos estágios anteriores, de nucleação, as interaçôes entre os atores dos diversos setores são raras, uma vez que estes se comportam como "ilhas" isoladas, preocupados com seus problemas internos e buscam estabilidade e afirmação. No terceiro estágio, com o crescimento, começam a ocorrer fortes interações entre os atores nacionais (governo, empresas, sistema educacional e comunidade) e destes com o exterior. Então, além da estratégia voltada para o crescimento, são acionadas estratégias para ordenar as interações e multiplicá-las, para dirimir conflitos e evitar superposições, para aumentar o fluxo de informaçóes e para estimular a geração e a transferência de tecnologias, endógenas e exógenas, para o setor produtivo.

No quarto estágio ocorre o amadurecimento do sistema. A formulação de políticas e estratégias de C\&T torna-se corriqueira e coerente com as políticas industrial, agrícola, relaçóes exteriores, defesa etc. A demanda nacional por tecnologia e serviços correlatos passa a ser crescentemente atendida por soluções e entidades nacionais, havendo inclusive exportação delas. Estratégias são formuladas para o aperfeiçoamento contínuo do sistema, tendo agora como focos a produção científica de vanguarda e a geração de inovações em produtos, processos e serviços. Intensificase o relacionamento internacional na área.

No caso do Brasil, o primeiro estágio estendeu-se até o final da Segunda Grande Guerra. As instituições criadas anteriormente ao conflito mencionado resultaram de respostas a desafios concretos enfrentados pelos governos, principalmente nas áreas de educação, da saúde e da agricultura. São exemplos desse período a criação do Jardim Botânico do Rio de Janeiro (1808), do Museu Nacional (1818), do Observatório Nacional (1827), do Museu Paraense Emílio Goeldi (1866), da Escola de Minas de Ouro Preto (1876), do Instituto Agronômico de Campinas (1887), do Laboratório Bacteriológico do Estado de São Paulo (1892), do Instituto Seroterápico Federal (1900), do Instituto Butantã (1901), do Instituto Vital Brazil (1919) e do Instituto Nacional de Tecnologia (1921). 
Pode-se afirmar que o processo de institucionalização de políticas e o desenvolvimento de um sistema articulado de C\&T começou a esboçar-se no Pós-Grande Guerra, principalmente a partir dos anos 1950, quando se iniciou a nucleação programada com a criação, em 1951, da Coordenação do Aperfeiçoamento do Pessoal do Ensino Superior - CAPES e do Conselho Nacional de Pesquisas - CNPq, o segundo em linha de subordinação direta ao Presidente da República. Seguiu-se a criação do IMPA (1952), do INPA (1952), do Banco Nacional de Desenvolvimento EconômicoBNDE (1952), do Instituto Brasileiro de Bibliografia e Documentação - IBBD (1954), da CNEN (1956), do Instituto de Pesquisas da Marinha - IPqM(1959), do Instituto de Energia Nuclear - IEN (1962), do CENPES-Petrobras (1963), do COPPE-UFRJ (1964) e do Instituto Nacional de Propriedade Industrial - INPI (1970). Essa nucleação foi acelerada a partir de 1964 pelo governo militar então instaurado. De acordo com a doutrina de "segurança e desenvolvimento" formulada pelos militares, a capacitação nacional em ciência e em tecnologia era considerada fundamental. O objetivo estratégico era transformar o Brasil numa "potência emergente" razoavelmente independente dos polos de poder existentes em nível mundial (Longo, 2000).

$\mathrm{O}$ primeiro instrumento financeiro de apoio ao desenvolvimento de ciência e tecnologia foi o Fundo de Desenvolvimento Tecnológico - FUNTEC, criado em 1964 no BNDE. Esse Fundo teve um papel relevante nos anos 1960, perdendo paulatinamente importância até a sua extinção em 1975.

Localizado no BNDE, mas funcionando com recursos do BID e da USAID, em 1965 foi criado o FINEP, Fundo de Financiamento de Estudos e Projetos e Programas, de natureza contábil e dirigido por uma Junta Coordenadora presidida pelo Ministro de Planejamento. Sua finalidade era prover recursos para financiar a elaboração de estudos de viabilidade de programas e propostas de investimento.

Em 1967, foi criada a FINEP - Financiadora de Estudos e Projetos, empresa do setor público, que sucedeu ao fundo assumindo seus direitos e obrigações, devendo ainda avaliar a viabilidade de projetos de investimentos para o Ministério de Planejamento.

Em 1968 foi promulgado o Plano Estratégico de Desenvolvimento, que, pela primeira vez, explicitava a questão científica e tecnológica como objeto de política governamental. O FNDCT surgiu no contexto do aludido plano. $\mathrm{O}$ fato é que até o final da década de 1960 o financiamento da pesquisa era feito no nível individual, diretamente ao pesquisador, e não adequado para dar suporte de maneira flexível à expansão pretendida e sendo planejada para a área científica e tecnológica. Para sanar essa lacuna, foi criado o Fundo Nacional de Desenvolvimento Científico e 
Tecnológico - FNDCT, em 31 de julho de 1969, pelo decreto-lei n.719, "com a finalidade de dar apoio financeiro aos programas e projetos prioritários de desenvolvimento científico e tecnológico, notadamente para a implantação do Plano Básico de Desenvolvimento Científico Tecnológico - PBDCT", que, por sua vez, deveria detalhar o Plano Nacional de Desenvolvimento - PND na área da ciência e da tecnologia.

O mesmo decreto-lei previu que a aplicação dos recursos do fundo obedeceria

"a diretrizes, planos e normas expedidas por um Conselho Diretor, constituido pelo Ministro do Planejamento e Coordenação Geral, como Presidente, pelo Presidente do CNPq, como Vice-Presidente, pelo Presidente do BNDE e por representantes do MEC, do Ministério das Minas e Energia, do Ministério da Induistria e do Comércio, e de outros setores, públicos e privados, ligados ao desenvolvimento cientifico e tecnológico nacional, conforme se dispuser em Decreto".

Tal determinação só foi implementada algumas décadas depois, como veremos mais adiante.

O decreto previa ainda que o fundo seria "dotado de uma Secretaria-Executiva cuja organização e funcionamento" seriam "estabelecidos em Regulamento". Tal determinação foi atendida quase um ano depois, com o decreto n.68.748, de 15 de junho de 1971, que atribuiu essa função à Financiadora de Estudos e Projetos - FINEP.

Em 1972, foi criado na FINEP o programa Apoio à Consultoria Nacional ACN, em complementação ao já existente programa de Apoio ao Usuário dos Serviços de Consultoria - AUSC, constituindo-se ambos, na ocasião, nos principais mecanismos de apoio às atividades de pré-inversão. Em 1973, a FINEP deu início ao Programa de Apoio ao Desenvolvimento Tecnológico da Empresa Nacional ADTEN, cujo regulamento foi aprovado em 1976, estabelecendo seus objetivos e formas de alocação de recursos.

Sob o ponto de vista operacional, estava dotada a agência FINEP de mecanismos de apoio capazes de cobrir todas as fases de um projeto, "ou seja: pesquisa básica - pesquisa aplicada - desenvolvimento experimental - estudo da viabilidade econômica - engenharia final", assegurando "a continuidade da seqüência 'pesquisaempreendimento"' (FINEP, 1973). A FINEP, inicialmente concebida para apoiar as empresas de consultoria, tornou-se uma agência singular, uma vez que passou a atuar em todo o espectro do desenvolvimento científico e tecnológico. 
Com a feliz simbiose FNDCT-FINEP, estava criada a mais importante fonte de recursos e o mais poderoso instrumento de desenvolvimento científico e tecnológico que o país viria a dispor nos 40 anos que se seguiram.

$\mathrm{Na}$ realidade, hoje, é muito difícil tratar do FNDCT isoladamente, ou seja, sem considerar a financiadora responsável pela sua operacionalização.

Em 1970, dando início ao funcionamento FNDCT, foram contratados apenas sete projetos, sendo beneficiários a Comissão Nacional de Energia Nuclear-CNEN, o Ministério da Marinha, a CAPES, a Academia Brasileira de Ciências - ABC, em dois casos, o Centro Técnico Aeroespacial - CTA do Ministério da Aeronáutica e a Pontifícia Universidade Católica do Rio de Janeiro - PUC-RJ.

Assim, a fase de nucleação programada prosseguiu com ímpeto novo, alavancada pelo fundo, dotado de orçamento crescente no período 1970-1978 (Figura 1). Raras são as instituições criadas no período que não contaram com recursos do FNDCT. Seguiram-se em criação: CEPED (1970), CETEC (1972), CIENTEC (1972), INMETRO (1973), CEPEL (1974), CPqD, CETEM (1978), NUTEC (1978), CTEx (1979), além de outras aqui não mencionadas.

Outros fatos relevantes ocorreram no período como a criação da STI, Secretaria de Tecnologia Industrial do então MIC, Ministério da Indústria e Comércio (1972), do CEBRAE (1972), da SEMA (1974) e da SEI (1979), a promulgação do I PBDCT (1973), a transformação do CNPq em Conselho Nacional do Desenvolvimento Científico e Tecnológico (1974), a implementação da Política Nacional de PósGraduação-PNPG (1975), a formalização do Sistema Nacional de Desenvolvimento Científico e Nacional -SNDCT e a aprovação do II e III PBDCTs (1976 e 1980).

Nesse período, o FNDCT recebeu recursos de empréstimos tomados pela União no Banco Interamericano de Desenvolvimento - BID, a saber: US\$25,8 milhōes (BID 361 SF-BR em 1973), US\$ 6,2 milhōes (BID 250 OC-BR em 1973) e US\$ 40 milhōes (BID 327 OC-BR em 1977).

Ainda merecem menção e considerações a participação do fundo na formação de administradores de pesquisa, a sua importância para a institucionalização da pós-graduação nas universidades brasileiras, o repasse de recursos feitos para outras instituiçōes federais e o número e porte dos projetos contratados no período, que serão abordados a seguir.

Em 1973, diante da importância da qualificação profissional, em nível gerencial, com vistas ao esforço de modernização das empresas nacionais, a SEPLAN deu início à execução do Programa Nacional de Treinamento de Executivos-PNTE. A FINEP, que, desde 1971, com recursos do FNDCT, já apoiava um programa do IPEA com 
FIGURA 1

FNDCT - Desembolsos efetuados de 1970 a 2008

Reais milhões - Média anual (IGP-DI - dez., 2008)

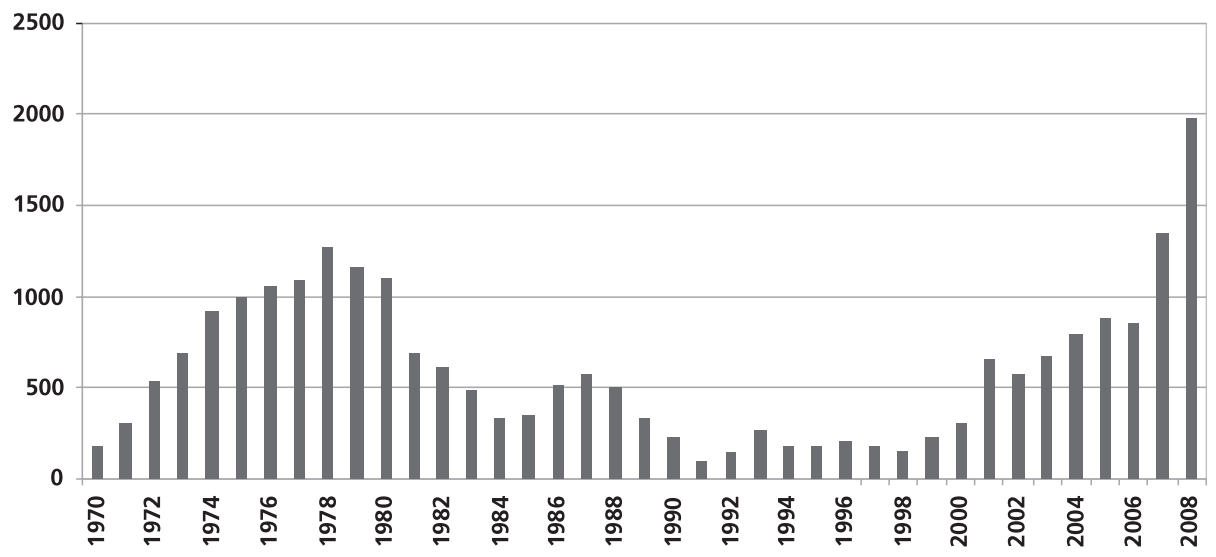

Fonte: FINEP.

o objetivo de aumentar, em qualidade e quantidade, o número de planejadores e administradores para o desenvolvimento tecnológico, iniciou sua participação na implementação do PNTE. Assim, em continuidade ao programa do IPEA e visando institucionalizar no Brasil a formação e o treinamento de pessoal destinado a institutos de tecnologia em nível de gerente de pesquisas e desenvolvimento, a FINEP contratou para esse fim, em final de 1972, os serviços da firma consultora Arthur D. Little do Brasil. Como resultado, em 1973, a FINEP deu início, com recursos do FNDCT, ao Programa de Treinamento em Administração de Pesquisas Científicas e Tecnológicas - PROTAP com o objetivo principal de complementar a formação profissional dos administradores do setor científico e tecnológico do país (Ferrari, 2002).

Inicialmente, o programa funcionava por módulos semanais, em regime de internato num hotel fora do Rio de Janeiro. Embora mudando de formato e de locais de oferta, o programa seguiu, por muitos anos, qualificando técnicos de alto nível, pertencentes a instituições públicas e privadas do país.

"De 1974 a 1978 foram treinados, nos diversos ramos da administração de pesquisas cientificas e tecnológicas, cerca de 720 técnicos por intermédio de 64 seminários e reuniōes de trabalho. Foram também concedidas 20 bolsas de estudo para especialização no exterior com vistas a criar um quadro de instrutores para os cursos do 
PROTAP, bem como para as universidades brasileiras. Neste quadriênio, mais de 90 técnicos de 15 países da América Latina e do Caribe participaram de eventos do Programa. Cerca de 36 instrutores e consultores estrangeiros foram contratados para colaborar com o PROTAP." (FINEP, 1978)

Em 1968, o Congresso Nacional aprovou a Lei da Reforma Universitária, pela lei n.5.540, de 28/11/68, fixando normas de organização e funcionamento do ensino superior. Essa lei instituiu no Brasil o modelo norte-americano de ensino superior, compreendendo a relevância de pesquisa e da pós-graduação, a necessidade de campus universitário integrando as áreas do conhecimento, a adoção do sistema de créditos, a fragmentação do ano letivo, a divisão do currículo em uma parte geral e outra profissional, a valorização da carreira docente, a exigência de docentes em tempo integral, a organização por departamentos especializados etc.

Essa lei foi de fundamental importância para consolidar o sistema universitário brasileiro, uma vez que exigia dedicação da instituição não só ao ensino, mas à pesquisa e aos serviços de extensão, para atender necessidades da sociedade.

A pós-graduação, graças principalmente à ordenação acadêmica da LRU, prosperou rapidamente, impulsionada pelo Ministério da Educação, através da CAPES, secundada pelo CNPq e por substanciais recursos do FNDCT alocados pela FINEP. As três agências tiveram papel importante para que a pós-graduação no Brasil se constituísse num caso de sucesso. A primeira, aportando recursos para a realização da pesquisa acadêmica, e a segunda com bolsas adicionais àquelas oferecidas pela CAPES aos alunos de pós-graduação, além de auxílios para o sustento da pesquisa individual dos professores (em geral projetos de menor monta que aqueles financiados pelo FNDCT, via FINEP).

Quanto ao FNDCT,

"a forma usual de operação do Fundo nesse periodo foi a contratação de projetos de alto valor, quase sempre pelo prazo de 2 anos, onde havia grande flexibilidade na utilização de recursos, que cobriam obras civis, equipamentos, material de consumo, salários e tudo o mais que fosse necessário para instalar e consolidar um grupo de pesquisa, um programa de pós-graduação ou um departamento universitário como um todo. A maneira pela qual estes apoios eram concedidos aliavam uma relação técnica com as lideranças científicas a uma relação jurídica com a universidade ou o instituto de pesquisa. Nesse sentido inovavam em relação à tradição brasileira de financiamento à pesquisa, ancorada nas relaçôes técnicas e jurídicas estabelecidas 
diretamente com o pesquisador, conforme as práticas do CNPq e da FAPESP. $O$ modo de atuar dos apoios FINEP tinha como objetivo dificultar que os recursos para pesquisa fossem alvo de disputa com outras atividades (politicamente mais fortes) da universidade, o que aconteceria se fossem diluidos nos orçamentos universitários. A esse tipo de apoio deu-se o nome de 'apoio institucional', com a dupla intenção de, por um lado, caracterizar a diferença em relação aos grants individuais e, por outro, de caracterizá-los como um aporte global de recursos com vistas à implantar e consolidar uma ou várias unidades de pesquisa ou pós-graduação. Esse tipo de apoio era, pois, desvinculado da declaração detalhada das atividades a realizar, sendo a ênfase da proposta colocada nos objetivos institucionais almejados. $O$ apoio institucional, essencial para levar a bom termo a missäo a que o Fundo se propôs na década de 70, passou a ser alvo de críticas em momentos seguintes, de maior escassez financeira, por provocar dependência excessiva por parte dos grupos financiados" (Guimarães, 1993).

Muito questionado pelos técnicos da FINEP e pela parcela da comunidade não beneficiada, o apoio institucional acabou sendo substituído, na década de 1980, pelo julgamento e pela contratação de projeto a projeto,

Um dos indicadores da importância do FNDCT no processo de institucionalização da pesquisa científica e tecnológica no Brasil nos anos 1970 é o crescimento dos cursos de pós-graduação, que passaram de 125 em 1969 para 974 em 1979. Pode-se citar a pós-graduação de uma instituição, dentre tantas outras possíveis, como exemplo dessa importância e sucesso: a Coordenação dos Programas de Pós-Graduação em Engenharia - COPPE da UFRJ, beneficiária de vários apoios institucionais do FNDCT.

Com relação a repasses, a FINEP, como Secretaria Executiva do FNDCT, transferia recursos em volumes consideráveis para financiar programas do CNPq, da CAPES e também para o FUNTEC. Alem disso, a própria FINEP, a partir de 1976, passou a ser beneficiada de repasses, feitos pelo fundo para o seu programa ADTEN, com a aprovação, pelo Presidente da República, da Exposição de Motivos n.256, de 31 de agosto daquele ano. Também foram beneficiadas com recursos do FNDCT várias instituições pertencentes a setores contemplados pelos PBDCTs, a saber: Comissão Nacional de Energia Nuclear-CNEN, NUCLEBRÁS, INPE, então vinculado ao CNPq, CTA do Ministério da Aeronáutica, Diretoria de Pesquisa e Ensino Técnico do Exército, Diretorias de Ensino e de Administração do Ministério da Marinha, Instituto de Pesquisas da Marinha-IPqM, Diretoria de Hidrografia e 
FIGURA 2

FNDCT - número de projetos contratados

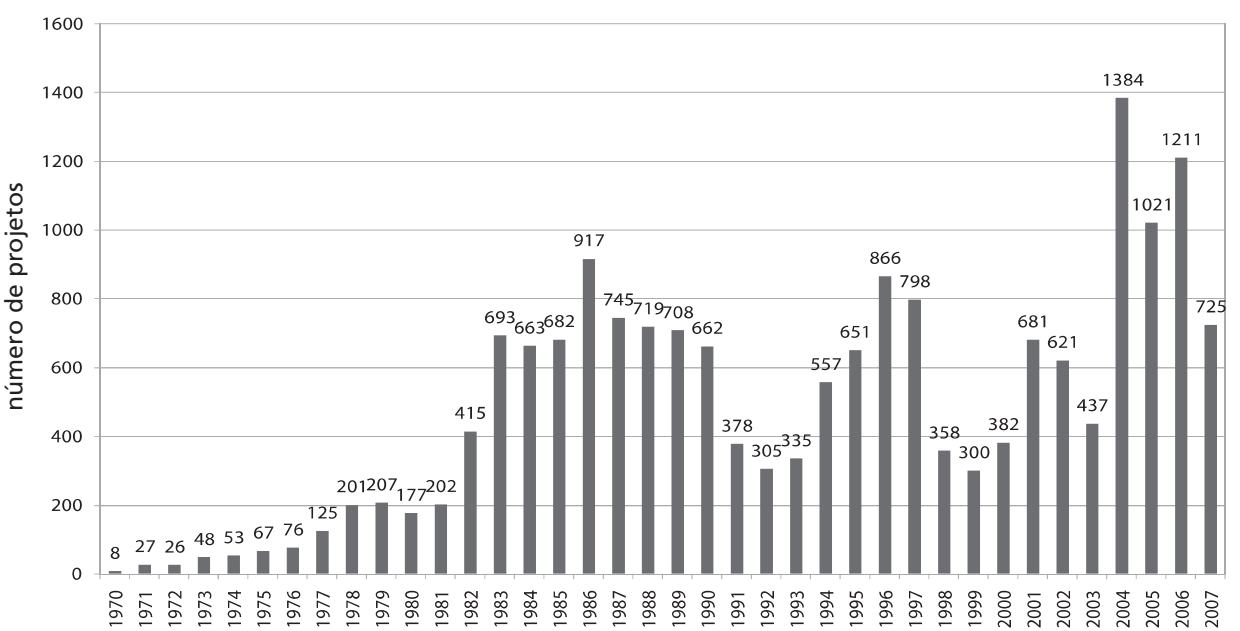

Fonte: FINEP.

Navegação do Ministério da Marinha, as estatais Usiminas e Digibrás e Sociedade Educacional Tupy, além de vários órgãos de outros ministérios e de estados. Em alguns casos, as transferências de recursos do FNDCT eram também feitas para a própria FINEP. Dessa maneira ela apoiou decisivamente os institutos de pesquisa e desenvolvimento dos governos estaduais como o CEPED da Bahia e o CETEC de Minas Gerais, e também os institutos setoriais do governo federal de diferentes ministérios, como o INMETRO, o CTEx e a Embrapa, além do IMPA, na ocasião subordinado ao CNPq, mais o Arquivo Nacional, o CPDOC da FGV, o IUPERJ, a Casa de Rui Barbosa, o Museu do Homem da UFMG e a Fundação João Pinheiro, entre outras instituições.

Finalmente, o período de nucleação caracterizou-se por recursos orçamentários crescentes (Figura 1), baixo número de operações (Figura 2) e elevado mas cadente valor médio por projeto ( Figura 3), sendo os valores fornecidos em reais referentes a dezembro de 2008. Pode-se atribuir o baixo número de operações de altos valores à disponibilidade de recursos e também aos repasses efetuados para outros órgãos, à modalidade de apoio institucional para a pesquisa e pós-graduação e à implantação de novas instituições.

Nucleados os órgãos principais do sistema até 1980, seguiu-se o período de crescimento e interaçôes entre os diversos atores do cenário científico e tecnológico 
FIGURA 3

FNDCT - valor médio por projeto

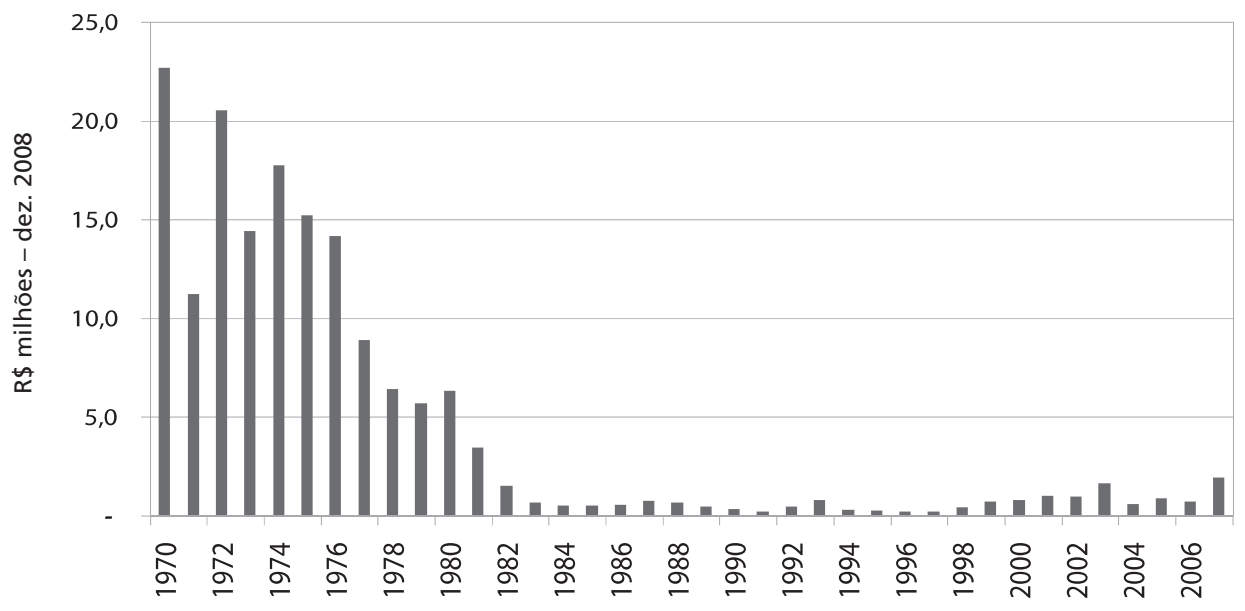

Fonte: FINEP

brasileiro, testando mecanismos e buscando funcionar articuladamente. Esse período, em virtude das conjunturas econômica e política adversas, se estendeu até o final dos anos 1990, freando o crescimento e retardando as interações esperadas.

A década de 1980 foi considerada perdida para o Brasil. A partir do segundo choque do petróleo, os país mergulhou numa crise econômica sem precedentes. Vários planos de estabilização econômica foram tentados sem sucesso, tendo a inflação alcançado a casa dos $80 \%$ ao mês em 1989.

Concomitantemente com a crise econômica, o país enfrentou contínuas turbulências políticas. Os militares, que governavam desde 1964, deixaram o poder em 1985, retornando o país ao regime democrático. O presidente civil eleito na ocasião faleceu antes de tomar posse, tendo assumido o seu vice. O presidente seguinte, eleito em 1989, promoveu o ingresso do país na globalização, sem qualquer estratégia que protegesse os interesses nacionais, abrindo o seu mercado à invasão estrangeira sem contrapartida e/ou salvaguardas. Tudo em nome de uma pretensa modernização a qualquer custo. Tal presidente foi destituído pelo Congresso Nacional em 1992, assumindo o governo o vice-presidente, que governou até dezembro de 1994. A partir daí, até os dias atuais, o país tem gozado de normalidade política, com crescimento econômico moderado e baixa inflação. 
$\mathrm{Na}$ área científica e tecnológica, o período foi de grande instabilidade institucional. Em 1985, com a criação do MCT - Ministério de Ciência e Tecnologia, esperava-se que o sistema de C\&T caminhasse para o amadurecimento. Porém, em consequência da crise econômica, houve um retardo na evolução da área devido à perda de sua importância estratégica relativa e à aguda escassez de recursos que passou a ocorrer. Políticas industriais foram elaboradas e não cumpridas. Em 1989, o MCT foi extinto, aumentando a debilidade do sistema.

O MCT foi recriado em 1992 e o ministro então nomeado foi mantido no cargo até 1999, permitindo uma salutar continuidade nas políticas e estratégias então estabelecidas.

Em 1988, foi promulgada a nova Constituição da República Federativa do Brasil. Essa Constituição tem dois artigos que tratam da ciência e da tecnologia. Incentivados pelo parágrafo 5 do artigo 218, vários estados e municípios criaram órgãos de fomento ao desenvolvimento científico e tecnológico, e alguns estados estruturaram sistemas próprios, coordenados por uma secretaria de C\&T.

Na década de 1990, a FINEP e o FNDCT voltaram a constar com empréstimos do BID tomados pela União, a saber: US\$ 100 milhões (BID 620 OC-BR em 1991), dos quais US\$ 60 milhões para o FNDCT, e US\$ 160 milhões (BID 880 OC-BR em 1996), dos quais US\$ 96 milhões para o FNDCT.

Tendo em vista a importância da engenharia para o desenvolvimento tecnológico, em 1995, a FINEP resolveu utilizar parte dos recursos do FNDCT oriundo do BID 880 OC-BR para impulsionar o desenvolvimento do ensino e da pesquisa em engenharia. Assim, tendo como parceiros o CNPq, a CAPES e a SESu - Secretaria de Educação Superior do MEC, criou o Programa de Desenvolvimento das Engenharias - PRODENGE.

O programa era composto de dois subprogramas: Reengenharia do Ensino da Engenharia-REENGE e Redes Cooperativas de Pesquisa-RECOPE, que contaram com a ordem de US\$ 50 milhões do FNDCT.

O RECOPE fomentou o trabalho conjunto de empresas, institutos e universidades em redes de pesquisas criadas sobre temas julgados prioritários para o desenvolvimento econômico e/ou social do país.

Os temas, definidos através de consulta a 500 especialistas, são abaixo listados:

- automação industrial;

- processos avançados de transformação metal-mecânica;

- aplicações da informática à engenharia; 
- engenharia de transporte;

- engenharia agroindustrial: alimentos;

- engenharia e gestão de recursos hídricos;

- saneamento básico;

- educação tecnológica.

Temas de interesse regional foram abordados em parceria com os estados, que se dispuseram a aportar metade dos recursos necessários aos projetos, ficando a outra metade por conta do orçamento do RECOPE.

Adicionalmente, as empresas puderam apresentar projetos que não se enquadravam nas prioridades levantadas pelos órgãos federais ou das propostas dos estados, mas nos quais já estivessem atuando cooperativamente com outras entidades.

Ao final de 1999, estavam trabalhando cooperativamente nas diversas redes um total de 248 grupos de pesquisa situados em universidades e institutos, ao lado de 142 empresas e outras entidades. Para as empresas envolvidas, a FINEP ofereceu recursos provenientes dos programas de financiamento normalmente utilizados por ela.

O REENGE provocou uma reflexão sobre o perfil do engenheiro que deveria ser formado, tendo em vista a dinâmica evolutiva a que estão sujeitas as sociedades modernas, as constantes mudanças de padrão tecnológico e o crescente nível científico exigido pelas inovaçôes. Em seguida, foram exercitadas propostas pedagógicas e metodológicas, para que se conseguisse preparar o futuro engenheiro com o desejado. A partir dos resultados obtidos, os participantes foram encorajados a alterar a concepção dos cursos. Adicionalmente, parte dos recursos do subprograma foi destinada a modernizar laboratórios, principalmente aqueles das áreas de ciências (física, química, biologia), matemática e computação, imprescindíveis para a formação de engenheiros. Ao todo participaram e foram contempladas, com recursos das 4 agências, 44 escolas de engenharia.

Paralelamente, foi concluída a montagem de um sistema de divulgação, interação e de ensino a distância, utilizando meios eletrônicos de comunicação. Em agosto de 1996, com recursos do FNDCT, entrou em funcionamento a Rede Brasileira de Engenharia - RBE, interligando por televisão, via satélite, cerca de cem escolas de engenharia do país.

Fato relevante ocorreu quando, em janeiro de 1996, foi criado o Conselho Nacional de Ciência e Tecnologia - CCT, presidido pelo Presidente da República, secretariado pelo MCT e composto por ministros e por pessoas representativas do meio científico e tecnológico. O CCT tem o encargo de formular a política nacional de C\&T, integrando e coordenando as ações de todos os ministérios. 
Finalmente, o orçamento do FNDCT, que começara a cair em 1979, teve a queda acentuada nos anos seguintes (Figura 1). Com a criação do MCT em 1985, ocorre uma ligeira recuperação que, porém, não se sustentou, atingindo o FNDCT o seu valor mais baixo em 1991 e, daí em diante, seguiu oscilando em valores baixos até o final da década. Como resultado do natural crescimento da comunidade científica e tecnológica, do fim das operações de repasse e de apoios institucionais, ocorreu um aumento acentuado no número de projetos contratados com recursos do fundo, com dois picos, um em 1986 e outro em 1996 (Figura 2). O valor médio por projeto continuou caindo até 1983 , permanecendo daí até o final da década com valores inferiores a $\mathrm{R} \$ 800$ mil (Figura 3).

Cumpre aqui salientar que, durante o período de escassez de recursos do FNDCT, décadas de 1980 e 1990, o Governo Federal negociou e contou com um empréstimo do Banco Mundial para o desenvolvimento científico e tecnológico. O empréstimo, que previa o investimento em iguais quantias pela União e pelo banco, deu origem ao Programa de Apoio ao Desenvolvimento Científico e Tecnológico PADCT, formulado em conjunto pelas agências federais FINEP, CNPq, CAPES e STI, que haviam constatado lacunas no desenvolvimento de diversos setores prioritários de C\&T.

As carências diagnosticadas referiam-se tanto às bases institucional e de infraestrutura, como à disponibilidade imediata de recursos. As lacunas identificadas na infraestrutura do SNDCT, comuns a todos os setores e áreas de conhecimento, foram: educação científica, informação em $C \& T$, insumos para $P \& D$, instrumentação científica, manutenção de equipamentos de pesquisa e política e administração de C\&T. Os setores e áreas prioritários do PADCT identificados na época como carentes de esforços e de suporte concentrado eram: química e engenharia química, biotecnologia, geociências e tecnologia mineral e tecnologia industrial básica (Teixeira \& Rappel, 1991). Essas carências deram origem aos diversos subprogramas do PADCT. Posteriormente, foram acrescentadas mais duas áreas: materiais e ciências ambientais.

Embora o agente financeiro fosse a FINEP, os recursos não foram alocados ao FNDCT, e a gestão do PADCT ficou a cargo de uma Secretaria Executiva situada em Brasília. A fase de teste, que previa inovadores mecanismos de gerenciamento, ocorreu em 1984, com recursos nacionais. Aprovado o seu funcionamento, o PADCT contou com três empréstimos do Banco Mundial, realizados como seguem: BIRD 2.489 BR, US\$ 72 milhōes em 6/2/1985; BIRD 3.269 BR, US\$ 140 milhões em 15/2/1991, e BIRD 4.266 BR, US\$ 66,2 milhões em 17/3/1998. 
O fato é que, ao término da década de 1990, faltavam recursos e mecanismos mais efetivos para a interação mais intensa entre os atores do cenário científicotecnológico-empresarial nacional. Mas, exatamente no final dessa década, começou a tomar forma e a estruturar-se o mecanismo que alteraria completamente o panorama descrito, revertendo a situação de penúria do FNDCT e abrindo caminho para o enfrentamento da questão de melhor interação produtiva entre os atores mencionados.

O acontecimento mais auspicioso ocorrido no final da década de 1990 foi a destinação, através da lei n.9.478 de 16 de agosto de 1997, de um percentual dos royalties sobre a produção de petróleo, para o Ministério da Ciência e Tecnologia. Em cada contrato de concessão de exploração de petróleo, é fixado o royalty devido pela Agência Nacional de Petróleo - ANP, podendo esse valor situar-se entre 5\% e $10 \%$, dependendo dos riscos geológicos, das expectativas de produção e de outros fatores pertinentes. Da parcela do valor do royalty que exceder a $5 \%$ da produção, $25 \%$ serão destinados "ao Ministério da Ciência e Tecnologia para financiar programas de amparo à pesquisa científica e ao desenvolvimento tecnológico aplicados à indústria do petróleo”. Do total dos referidos recursos, “40\%, no mínimo, serão aplicados em programas de amparo a pesquisa de desenvolvimento tecnológico para a indústria do petróleo nas regiões Norte e Nordeste". Tal medida, evidentemente, busca diminuir as notórias desigualdades regionais existentes, também, na área de C\&T do país.

Em novembro de 1998, através do decreto n.2.851, os referidos royalties devidos ao MCT foram destinados ao FNDCT, ou seja, passaram a ser administrados pela FINEP, Secretaria Executiva do Fundo. Com tal decisão, evitou-se a criação de uma nova agência, abrindo-se perspectivas novas de revitalização do FNDCT através de recursos não dependentes do orçamento da União, alocados com regularidade e, hipoteticamente, sem barreiras.

A partir dessas medidas, foi criado o Fundo Setorial de Petróleo e Gás NaturalCTPetro, que teve sua operação iniciada em 1999, com aplicaçóes que totalizaram R \$ 37 milhôes.

Criou-se, então, a expectativa de que outros fundos que fossem criados (principalmente a partir da concessão de exploração de serviços outorgada pelo Governo Federal) viessem a ter a mesma destinação, ou seja, colocados no FNDCT, que se tornaria um grande fundo, voltado principalmente para o desenvolvimento de setores definidos pela origem dos recursos.

A partir de abril de 2000, o governo deu início ao atendimento de tal expectativa, propondo ao Congresso, com sucesso, a criação de outros fundos setoriais. 
Hoje estão em funcionamento 16 fundos, sendo 14 relativos a setores específicos (aeronáutica, agronegócio, Amazônia, aquaviário, biotecnologia, energia, espacial, hidroviário, informática, mineral, petróleo e gás, saúde, transporte, telecomunicações) e 2 gerais, um voltado à interação universidade-empresa (FVA - Fundo Verde-Amarelo) e o outro é destinado a apoiar a melhoria da infraestrutura de ICTs (Infraestrutura). Somente um dos fundos setoriais não foi colocado no FNDCT, o FUNTTEL - Fundo para Desenvolvimento Tecnológico das Telecomunicações, sendo administrado pelo Ministério das Comunicações.

As receitas dos fundos são oriundas de contribuições incidentes sobre o resultado da exploração de recursos naturais pertencentes à União, parcelas do Imposto sobre Produtos Industrializados (IPI) de certos setores e de Contribuição de Intervenção no Domínio Econômico (CIDE) incidente sobre os valores que remuneram o uso ou aquisição de conhecimentos tecnológicos/transferência de tecnologia do exterior.

Em 2004, com o objetivo de integrar suas ações, foi criado o Comitê de Coordenação dos Fundos Setoriais, formado pelos presidentes dos Comitês Gestores, pelos presidentes da FINEP e do CNPq, sendo presidido pelo Ministro da Ciência e Tecnologia. Dentre as medidas implementadas pelo comitê, cabe salientar a implantação das chamadas Ações Transversais, orientadas para os programas estratégicos do MCT, que utilizam recursos de diversos fundos setoriais para uma mesma ação.

Desde a incorporação dos Fundos Setoriais ao FNDCT, este voltou efetivamente a ser o principal instrumento do Governo Federal para alavancar o sistema de CT\&I do país.

A Figura 1 mostra como foi significativa a recuperação do FNDCT a partir de 1999, e o seu orçamento em 2007, pela primeira vez, ultrapassou aquele correspondente a 1978. Concomitantemente, o número de projetos aumentou bastante e o valor médio deles cresceu apenas moderadamente.

A realidade é que, graças aos Fundos Setoriais e às Ações Transversais, têm sido possível ao FNDCT financiar milhares de novos projetos em Instituições de Ciência e Tecnologia, ICTs, que objetivam não somente a geração de conhecimento, mas também sua transferência para o setor produtivo. $\mathrm{O}$ incentivo à formulação de projetos de parcerias entre empresas e ICTs tem resultado numa maior interação entre os atores do sistema e estimulado maior investimento em inovação tecnológica por parte das empresas. Isso tem contribuído para um maior equilíbrio na relação entre investimentos públicos e privados em pesquisa e desenvolvimento experimental. 
Concomitantemente com a recuperação do fundo, no início da década atual e incentivado pelo MCT, ocorreu uma mudança de postura conceitual, alterando-se a visão do chamado "sistema nacional do desenvolvimento científico e tecnológico", formalizado na década de 1970, para a concepção de "sistema nacional de inovação", com uma abrangência mais ampla dos atores e das relaçôes que levam a um objetivo claramente identificado: a inovação. Mais do que antes, o sistema e seus componentes passaram a ser avaliados pelos seus resultados, principalmente em termos de inovaçôes em benefício do setor produtivo e das necessidades sociais do país. A inovação passou a ser preocupação central e explícita nos planejamentos, nas políticas e estratégias governamentais e privadas, orientando a alocação dos recursos disponíveis.

Um evento decisivo para acelerar as interaçōes e finalizar o terceiro estágio da evolução do sistema de C\&T ocorreu em 2005, com a regulamentação, através do decreto n.5.563/2005, da lei n.10.973/2004, mais conhecida como Lei de Inovação.

A lei contempla três objetivos: a constituição de ambiente propício a parcerias estratégicas entre universidades, institutos tecnológicos e empresas; o estímulo à participação de institutos de ciência e tecnologia no processo de inovação; e o estímulo à inovação na empresa, principalmente, através do instrumento da subvenção, que prevê o aporte de recursos públicos, não reembolsáveis, diretamente às empresas, beneficiando empresas inovadoras.

A lei estabelece ainda dispositivos legais para a incubação de empresas no espaço público e a possibilidade de compartilhamento de infraestrutura, equipamentos e recursos humanos, públicos e privados, para o desenvolvimento tecnológico e a geração de inovações de produtos e de processos. Cria também regras claras para a participação de pesquisadores públicos nos trabalhos de inovação tecnológica desenvolvidos no setor produtivo. Quanto ao valor da subvenção, este é definido anualmente por meio de portaria interministerial e tem como fonte de recursos o FNDCT. O decreto estabelece que na alocação dos recursos deverão ser seguidas as prioridades definidas na Política Industrial, Tecnológica e de Comércio Exterior (PITCE), embora não exclusivamente.

Embora muito se tenha que aprender e melhorar com a prática, a introdução da subvenção entre os mecanismos de apoio ao desenvolvimento científico e tecnológico tem sido considerada um sucesso desde o seu início de operação em 2006. A Tabela 1 apresenta o desempenho da subvenção até a presente data. A Figura 4 fornece, a partir de 1998, as operações de crédito da FINEP, juntamente com aquelas efetuadas com recursos do FNDCT, tanto para as operações tradicionais como as de subvenção. 
TABELA 1

Subvenção econômica

\begin{tabular}{lcccc}
\hline & 2006 & 2007 & 2008 & 2009 \\
Demanda & 1.100 & 2.568 & 2.665 & 2.558 \\
Projetos & 1,9 & 2,5 & 6,2 & 5,2 \\
R\$ solicitados & & & & \\
Atendimento & 145 & 174 & 245 & - \\
Projetos & 300 & 450 & 450 & - \\
Disponíveis milhões de reais & & & & \\
Contratados milhões de reais & 274 & 313 & 514 & \\
\hline
\end{tabular}

Fonte: FINEP.

Através do Programa de Apoio à Pesquisa em Empresas - PAPPE, concebido para ser coordenado pela FINEP e ser executado em parceria com as agências de apoio à pesquisa nos estados, o mecanismo de subvenção foi disseminado e ampliado no país. O PAPPE atua em apoio direto ao pesquisador, associado a uma empresa já existente ou em criação, financiando o seu projeto de pesquisa de criação de um novo produto ou processo. Já em 2008, os editais do PAPPE Subvenção contaram com R \$ 150 milhões do FNDCT e R \$ 95 milhões de agências de 17 estados.

Logo após completar os 40 anos, finalmente o FNDCT, através da lei n.11.540 de 12 de novembro de 2007, regulamentada pelo decreto n.6.938 de 13 de agosto de 2009, foi dotado de um Conselho Diretor, conforme previsto pelo decreto n.719 de julho de 1969, que o criou. Tal conselho, vinculado ao MCT, tem a seguinte composição: é presidido pelo Ministro de Estado da Ciência e Tecnologia; tem representantes do Ministério da Educação, do Ministério do Desenvolvimento, Indústria e Comércio Exterior, do Ministério do Planejamento, Orçamento e Gestão, do Ministério da Defesa, do Ministério da Fazenda; o Presidente da Financiadora de Estudos e Projetos - FINEP; o Presidente do Conselho Nacional de Desenvolvimento Científico e Tecnológico - CNPq; o Presidente do Banco Nacional de Desenvolvimento Econômico e Social-BNDES; o Presidente da Empresa Brasileira de Pesquisa Agropecuária-EMBRAPA; três representantes da comunidade científica 
FIGURA 4

Evolução dos recursos para financiamentos por natureza

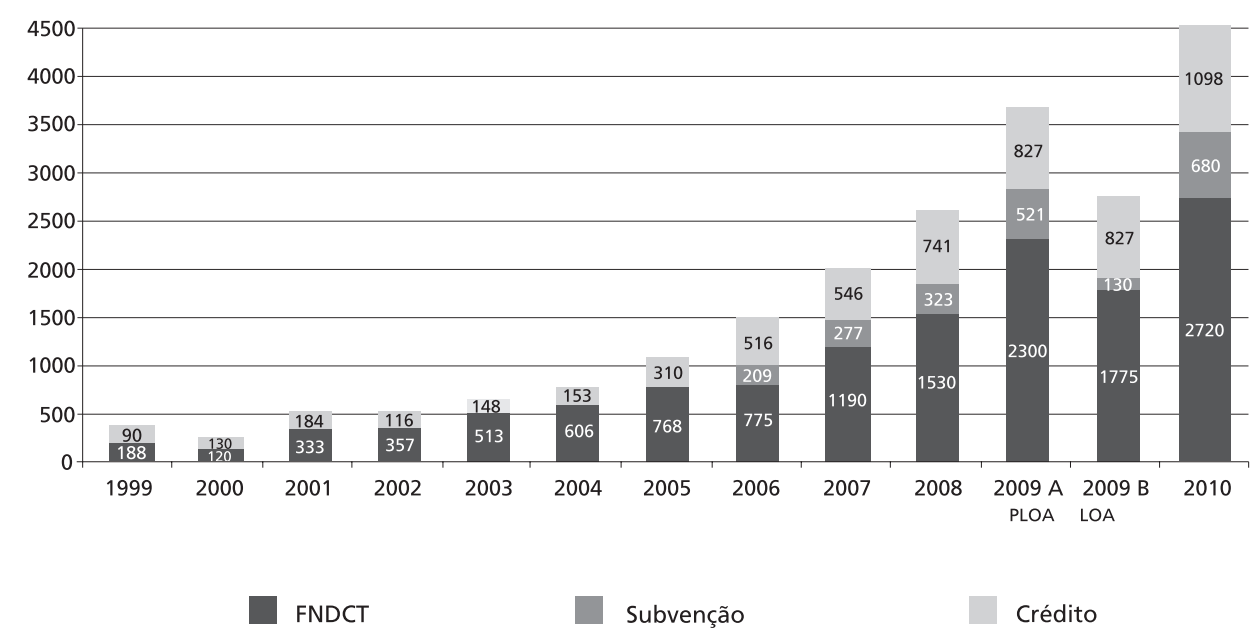

Fonte: FINEP.

e tecnológica; três representantes do setor empresarial, preferencialmente ligados à área tecnológica, sendo um representativo do segmento de microempresas e pequenas empresas, e um representante dos trabalhadores da área de ciência e tecnologia

Acelerado o estágio de crescimento e interação, considera-se que o assim chamado "sistema nacional de ciência, tecnologia e inovação" está adentrando o estágio de amadurecimento. O sistema está numa fase de transição. O país está dotado de um arcabouço físico e regulatório robusto e completo na área de CT\&I, na qual não se vislumbra um retrocesso.

Adentrando o estágio de amadurecimento, também está o FNDCT. Lastreado por 40 anos de credibilidade total na comunidade científica, tecnológica e, agora, também empresarial, o FNDCT está em franca recuperação financeira, bem administrado pela FINEP e dotado de um representativo Conselho Diretor, alçado na sua vinculação ao MCT.

Com um passado de realizações reconhecido nacionalmente, espera-se um futuro ainda mais profícuo para o FNDCT. 


\section{Referências bibliográficas}

Ferrari, A.F. "O Fundo Nacional de Desenvolvimento Científico e Tecnológico - FNDCT e a Financiadora de Estudos e Projetos - FINEP”, Revista Brasileira de Inovação, Rio de Janeiro, ano 1, v.1, p.151-187, jan.-jun., 2002.

FINEP. Relatório de atividades. Rio de Janeiro, 1973.

Relatório de atividades. Rio de Janeiro, 1978.

Guimarães, R. FNDCT: uma nova missão. Rio de Janeiro: EAE-FGV, MCT, BM, PADCT II, 1993.

Longo, W.P. "O desenvolvimento científico e tecnológico do Brasil”, Brasil: 500 Anos, Belém, UNAMA, v.II, 2000.

Paulinyi, E. "Ciência e tecnologia e decisões políticas", LS 21-86. Rio de Janeiro: Escola Superior de Guerra, 1986.

Teixeira, F.L.C.; Rappel, E. "PADCT: uma alternativa de gestão financeira para C\&T", Revista de Administração, São Paulo, v.26, n.4, p.113-118, out.-dez., 1991. 